\title{
Positron Annihilation Spectroscopy and Small Angle Neutron Scattering Characterization of Nanostructural Features in Irradiated Fe-Cu-Mn Alloys
}

B.D Wirth, P. Asoka-Kumar, R.H. Howell, G.R. Odette, P.A. Sterne

U.S. Department of Energy

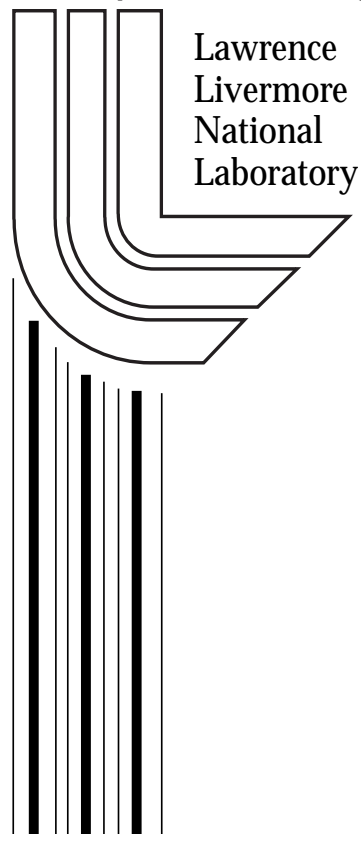

This article was submitted to Materials Research Society Fall 2000 Symposium R, Boston, MA, November 27 - December 1, 2000

\section{January 1, 2001}




\section{DISCLAIMER}

This document was prepared as an account of work sponsored by an agency of the United States Government. Neither the United States Government nor the University of California nor any of their employees, makes any warranty, express or implied, or assumes any legal liability or responsibility for the accuracy, completeness, or usefulness of any information, apparatus, product, or process disclosed, or represents that its use would not infringe privately owned rights. Reference herein to any specific commercial product, process, or service by trade name, trademark, manufacturer, or otherwise, does not necessarily constitute or imply its endorsement, recommendation, or favoring by the United States Government or the University of California. The views and opinions of authors expressed herein do not necessarily state or reflect those of the United States Government or the University of California, and shall not be used for advertising or product endorsement purposes.

This is a preprint of a paper intended for publication in a journal or proceedings. Since changes may be made before publication, this preprint is made available with the understanding that it will not be cited or reproduced without the permission of the author.

This work was performed under the auspices of the United States Department of Energy by the University of California, Lawrence Livermore National Laboratory under contract No. W-7405-Eng-48.

This report has been reproduced directly from the best available copy.

Available electronically at http://www.doc.gov/bridge

Available for a processing fee to U.S. Department of Energy

And its contractors in paper from

U.S. Department of Energy

Office of Scientific and Technical Information

P.O. Box 62

Oak Ridge, TN 37831-0062

Telephone: (865) 576-8401

Facsimile: (865) 576-5728

E-mail: reports@adonis.osti.gov

Available for the sale to the public from

U.S. Department of Commerce

National Technical Information Service

5285 Port Royal Road

Springfield, VA 22161

Telephone: (800) 553-6847

Facsimile: (703) 605-6900

E-mail: orders@ntis.fedworld.gov

Online ordering: http://www.ntis.gov/ordering.htm

OR

Lawrence Livermore National Laboratory

Technical Information Department's Digital Library

http://www.llnl.gov/tid/Library.html 


\title{
Positron Annihilation Spectroscopy and Small Angle Neutron Scattering Characterization of Nanostructural Features in Irradiated Fe-Cu-Mn Alloys
}

\author{
B. D. Wirth ${ }^{1}$, P. Asoka-Kumar ${ }^{1}$, R. H. Howell ${ }^{1}$, G. R. Odette ${ }^{2}$ and P. A. Sterne ${ }^{1}$ \\ ${ }^{1}$ Lawrence Livermore National Laboratory, Livermore, CA 94551 \\ ${ }^{2}$ University of California, Santa Barbara, Santa Barbara, CA 93106
}

\begin{abstract}
Radiation embrittlement of nuclear reactor pressure vessel steels results from a high number density of nanometer sized $\mathrm{Cu}-\mathrm{Mn}-\mathrm{Ni}$ rich precipitates (CRPs) and sub-nanometer matrix features, thought to be vacancy-solute cluster complexes (VSC). However, questions exist regarding both the composition of the precipitates and the defect character and composition of the matrix features. We present results of positron annihilation spectroscopy (PAS) and small angle neutron scattering (SANS) characterization of irradiated and thermally aged $\mathrm{Fe}-\mathrm{Cu}$ and $\mathrm{Fe}-$ $\mathrm{Cu}-\mathrm{Mn}$ alloys. These complementary techniques provide insight into the composition and character of both types of nanoscale features. The SANS measurements indicate populations of CRPs and VSCs in both alloys. The CRPs are coarser in the $\mathrm{Fe}-\mathrm{Cu}$ alloy and the number densities of CRP and VSC increase with the addition of Mn. The PAS involved measuring both the positron lifetimes and the Doppler broadened annihilation spectra in the high momentum region to provide elemental sensitivity at the annihilation site. The spectra in $\mathrm{Fe}-\mathrm{Cu}-\mathrm{Mn}$ specimens thermally aged to peak hardness at $450^{\circ} \mathrm{C}$ and irradiated at $288^{\circ} \mathrm{C}$ are nearly identical to elemental $\mathrm{Cu}$. Positron lifetime and spectrum measurements in $\mathrm{Fe}-\mathrm{Cu}$ specimens irradiated at $288^{\circ} \mathrm{C}$ clearly show the existence of long lifetime ( $\left.\sim 500 \mathrm{ps}\right)$ open volume defects, which also contain $\mathrm{Cu}$. Thus the SANS and PAS provide a self-consistent picture of nanostructures composed of CRPs and VSCs and tend to discount high Fe concentrations in the CRPs.
\end{abstract}

\section{INTRODUCTION}

Reactor pressure vessel (RPV) embrittlement results from hardening caused by a high number density of ultra-fine scale features formed during irradiation. A combination of theory $[1,2]$ and experimental techniques, including extensive three-dimensional atom probe (3DAP) [35] and small angle neutron scattering (SANS) [6-9] characterization, has established that nanometer sized Cu-Mn-Ni precipitates (CRPs), or clusters, are often the dominant embrittling feature in $\mathrm{Cu}$ bearing steels. A secondary embrittling feature, relatively independent of $\mathrm{Cu}$, accumulates with neutron dose and produces significant embrittlement at high fluence, even in low $\mathrm{Cu}$ steels [10]. The latter have been termed stable matrix features (SMFs) based on their post-irradiation annealing recovery kinetics $[2,8]$. Theory and atomistic simulations, as well as the annealing experiments, suggest that the SMFs are three dimensional, sub-nanometer vacancy-solute ( $\mathrm{Mn}, \mathrm{Cu}$ and $\mathrm{Ni}$ ) cluster complexes (VSCs) that initially form in displacement cascades $[2,9,11]$. The balance of CRPs and VSCs depends on the combination of metallurgical and irradiation variables $[2,11]$.

However, there is a significant controversy regarding the actual CRP composition [3$5,9,12]$ and up until now, the vacancy character of the SMFs has largely rested on interpretations of annealing signatures and simulation results $[2,8,9,11]$. While the 3DAP and SANS measurements generally reveal similar CRP-type feature number densities, sizes and $\mathrm{Mn}$ and $\mathrm{Ni}$ contents that are consistent with both SANS (see below) and theoretical predictions, they give very different views of their composition. The 3DAP results have been interpreted to suggest that the nanoscale solute clusters are $\mathrm{Cu}$ enriched, but contain significant quantities of $\mathrm{Fe}(>50 \%)[3-$ 
5]. In contrast, standard interpretation of a large body of SANS data, including on alloys with systematic variations in the key elements indicate the presence of well-formed CRPs that contain $\mathrm{Cu}$ (typically $\sim 70 \%$ ), $\mathrm{Ni}$ and $\mathrm{Mn}$, but little or no Fe [6-9]. There are also alternative candidates for SMFs, including interstitial cluster complexes, dilute atmospheres of solutes and other nanoscale phases associated with wide variety of elements $[2,4,11]$.

Both SANS and 3DAP have significant limitations. In principle, 3DAP offers the potential of near atomic resolution. However, the resolution is not absolute and is influenced by trajectory aberrations associated with the complex topology of the evaporation surface at CRPs and SMFs like VSC [5]. Due to the very small size of these features, positional uncertainties of $0.5 \mathrm{~nm}$ or less would artificially place significant numbers of iron atoms in a CRP and solute atoms in the adjoining iron matrix. The 3DAP technique also suffers from limited statistics associated with sampling very small material volumes, cannot detect defects or defect clusters and may experience preferential pre-evaporation of solute atoms. While SANS measurements sample much larger material volumes, the data analysis relies on assumptions, particularly regarding the magnetization of CRPs and SMFs, and suffers co-variance and non-uniqueness associated with de-convoluting the scattering contributions from multiple, size distributed scattering features.

The objective of this work is to use the combination of PAS and SANS to partly mitigate their individual limitations in characterizing the nanostructural features formed in irradiated Fe$\mathrm{Cu}$ and $\mathrm{Fe}-\mathrm{Cu}-\mathrm{Mn}$ alloys. The SANS technique provides information on the CRP size, number density and volume fractions, as well as providing insight on their compositions. The PAS technique is unique in its ability to detect the presence of vacancy and vacancy cluster trapping centers and most recently, the chemical composition of the trapping site as well. Further, positrons are also 'trapped' in $\mathrm{Cu}$ precipitates ${ }^{1}$. By combining PAS and SANS and other techniques, the potential exists to both help identify the basic defect character of the SMFs and to help resolve the discrepancy between the SANS and 3DAP views of precipitate composition.

\section{EXPERIMENT}

Binary $\mathrm{Fe}-0.9 \mathrm{wt} \% \mathrm{Cu}$ and ternary $\mathrm{Fe}-0.9 \mathrm{wt} \% \mathrm{Cu}-1.0 \mathrm{wt} \% \mathrm{Mn}$ alloys were solution annealed at $775^{\circ} \mathrm{C}$ for 17 hours followed by a 3-minute salt quench to $450^{\circ} \mathrm{C}$ prior to air-cooling. This heat treatment was intended to keep the $\mathrm{Cu}$ in supersaturated solution prior to irradiation or thermal annealing. Coupons of these alloys approximately $1 \mathrm{~cm} \times 1 \mathrm{~cm} \times 2 \mathrm{~mm}$ thick were thermally aged at $450^{\circ} \mathrm{C}$ for 24 hours and neutron irradiated at $288^{\circ} \mathrm{C}$ in a flux of about $7 \times 10^{15}$ $\mathrm{n} / \mathrm{m}^{2}-\mathrm{s}$ to a fluence of $0.9 \times 10^{23} \mathrm{n} / \mathrm{m}^{2}$.

The SANS experiments were performed at the National Institute of Science and Technology (NIST) Center for Neutron Research [14]. Small angle neutron scattering arises from both nuclear $(\mathrm{N})$ and magnetic $(\mathrm{M})$ scattering length density differences between the ferrite matrix and the scattering feature. Thus the samples were measured in a strong magnetic field $(\sim 1.7 \mathrm{~T})$ that saturated the iron matrix. The scattering from a well-collimated beam of $0.5 \mathrm{~nm}$ wavelength neutrons was recorded on a position sensitive detector with a maximum q-range of about $3 \mathrm{~nm}^{-1}$. The scattering data for the radiation induced features were calculated by subtracting background counts, parasitic scattering and normalized scattering from an unirradiated control specimen from the net scattering count recorded in each detector pixel. The corrected data were then converted to absolute scattering cross-sections, $\mathrm{d} \Sigma / \mathrm{d} \Omega$, by normalizing

\footnotetext{
${ }^{1}$ The physical mechanism responsible for positron confinement in CRPs is different than in the case of vacancy defects. Positron localization in CRPs results from the strong positron affinity of copper $(-4.81 \mathrm{eV})$ relative to iron $(-3.84 \mathrm{eV})$ [13], while vacancy trapping is due to missing ionic core(s) and a decreased electron density associated with an open volume defect.
} 
to a water reference sample, including standard accounting for transmission and sample volumes. The cross section data were then averaged over small increments of $\mathrm{q}$ and the angle $\phi$ with respect to the magnetic field direction.

The magnetic component of the $\mathrm{d} \Sigma / \mathrm{d} \Omega(\mathrm{q}, \phi)$ data were analyzed by least-squares fits assuming log-normal size distribution(s) of spherical scattering features. The features were assumed to act as magnetic holes in a saturated ferromagnetic iron matrix. Since the magnetic scattering contrast is precisely known, this assumption provides absolute estimates of the number density and volume fraction of the scattering features. The magnetic to nuclear $(\mathrm{M} / \mathrm{N})$ scattering ratio provides information about the composition of the scattering feature(s). In the case of simple binary and ternary $\mathrm{Fe}-\mathrm{Cu}-\mathrm{Mn}$ alloys, the $\mathrm{M} / \mathrm{N}$ ratio provides a relatively clear indication of precipitate composition. Additional details regarding the SANS experiments and analysis are provided elsewhere $[8,9]$.

The PAS measurements were performed using the Lawrence Livermore National Laboratory (LLNL) Pelletron facility. The Pelletron is a $3.0 \mathrm{MeV}$ electrostatic accelerator that forms a positron beam with a flux of $\sim 6.5 \times 10^{9} \mathrm{e}+/ \mathrm{m}^{2}-\mathrm{s}$ from a $70 \mathrm{mCi}{ }^{22} \mathrm{Na}$ source. The use of a high-energy positron beam allows the characterization of bulk specimens, which do not need to be mounted in vacuum and improves the signal to noise ratio by eliminating background radiation from the positron source. The experimental setup and methods to evaluate and deconvolute positron lifetime spectra and measure and interpret Doppler broadened annihilation spectra are described in more detail elsewhere $[15,16]$.

Briefly, thermalized positrons experience a repulsive potential from ionic cores and attractive potential from electrons and open volume defects. Thus vacancy features and regions with strong positron affinity, including nanovoids (VSCs) and CRPs, effectively 'trap' the positrons. Hasegawa and co-workers have shown that nearly all positrons localize and annihilate in a quantum dot type structure of nanoscale pure $\mathrm{Cu}$ precipitates formed in a thermally aged $\mathrm{Fe}$ $1.0 \% \mathrm{Cu}$ alloy [17]. Positron annihilation with electrons produces predominately two gamma rays, which are shifted up or down in energy (Doppler shifts) around $0.511 \mathrm{MeV}$ by an amount $\Delta \mathrm{E}=1 / 2 \mathrm{p}_{\mathrm{L}} \mathrm{c}$, where $\mathrm{p}_{\mathrm{L}}$ is the longitudinal component of the electron-positron momentum in the direction of gamma ray emission [16]. The $\Delta \mathrm{E}$ can be precisely determined with good signal to noise ratio using a coincidence, two detector setup. Annihilation with more localized $3 \mathrm{~d}$ transition metal electrons produce Doppler shifts that extend into the high momentum region. In contrast, annihilation with more spatially extended valence electrons in nanovoids makes a negligible contribution to $\Delta \mathrm{E}$ at high momentum. The exact shape of the $\Delta \mathrm{E}$ curves depends on the characteristics of the $3 \mathrm{~d}$ electrons, hence on the atomic species at the annihilation site. Thus, analysis of the high momentum region of the Doppler broadened curve can be used to determine the elemental composition of the trapping feature.

\section{RESULTS}

\section{Thermally aged alloys}

SANS and PAS characterization of the $\mathrm{Fe}-\mathrm{Cu}$ and $\mathrm{Fe}-\mathrm{Cu}-\mathrm{Mn}$ alloy following thermal aging at $450{ }^{\circ} \mathrm{C}$ for 24 hours indicate the presence of a high number density of nearly pure, defect free $\mathrm{Cu}$ precipitates. The SANS scattering cross-sections fit to a single, log-normal size distribution and resulted in mean radii, number densities and volume fractions of 0.9 and $1.3 \mathrm{~nm}$, $9 \times 10^{23}$ and $5 \times 10^{23} \mathrm{~m}^{-3}$ and 0.23 and $0.49 \%$ for the $\mathrm{Fe}-\mathrm{Cu}$ and $\mathrm{Fe}-\mathrm{Cu}-\mathrm{Mn}$ alloy, respectively. The measured magnetic to nuclear scattering ratio of 9.6 for the $\mathrm{Fe}-\mathrm{Cu}$ alloy is close to, but actually slightly higher than the value typically associated with a pure $\mathrm{Cu}$ precipitate $(\sim 7.6)$ [12]. This could be due to the presence of a small amount of $\mathrm{Fe}(\sim 10 \%)$. The value of 5.3 for the $\mathrm{Fe}-\mathrm{Cu}-\mathrm{Mn}$ alloy is consistent with precipitates containing about $96 \% \mathrm{Cu}$ and $4 \% \mathrm{Mn}$. 
A slight increase in the mean positron lifetime value was obtained for both thermally aged alloys from 109 ps (as-received control) to 114 ps (Fe-Cu) and from 110 to 114 ps (Fe-Cu$\mathrm{Mn})$. Figure $1 \mathrm{a}$ and $1 \mathrm{~b}$ show the normalized (to the as-received control) Doppler broadened spectra for the $\mathrm{Fe}-\mathrm{Cu}$ and $\mathrm{Fe}-\mathrm{Cu}-\mathrm{Mn}$ alloy, respectively. These Figures also show a reference spectrum for pure, well-annealed elemental $\mathrm{Cu}$. The thermally aged spectra from both the $\mathrm{Fe}-\mathrm{Cu}$ and $\mathrm{Fe}-\mathrm{Cu}-\mathrm{Mn}$ alloys are nearly identical to that of pure $\mathrm{Cu}$, indicating that the positrons are localized within nearly pure $\mathrm{Cu}$ precipitates, consistent with the results of Hasegawa et al [17]. Note the slightly lower ratio in the high momentum region of the $\mathrm{Fe}-\mathrm{Cu}-\mathrm{Mn}$ alloy is consistent with a small amount of $\mathrm{Mn}$ in the precipitates. The calculated positron lifetime of bec $\mathrm{Cu}$ is 110 ps, only slightly longer than the value of 107 ps calculated for both fcc $\mathrm{Cu}$ and bcc Fe. Thus, the slight increase in the mean positron lifetime with thermal aging is also consistent with pure $\mathrm{Cu}$, vacancy free precipitates.
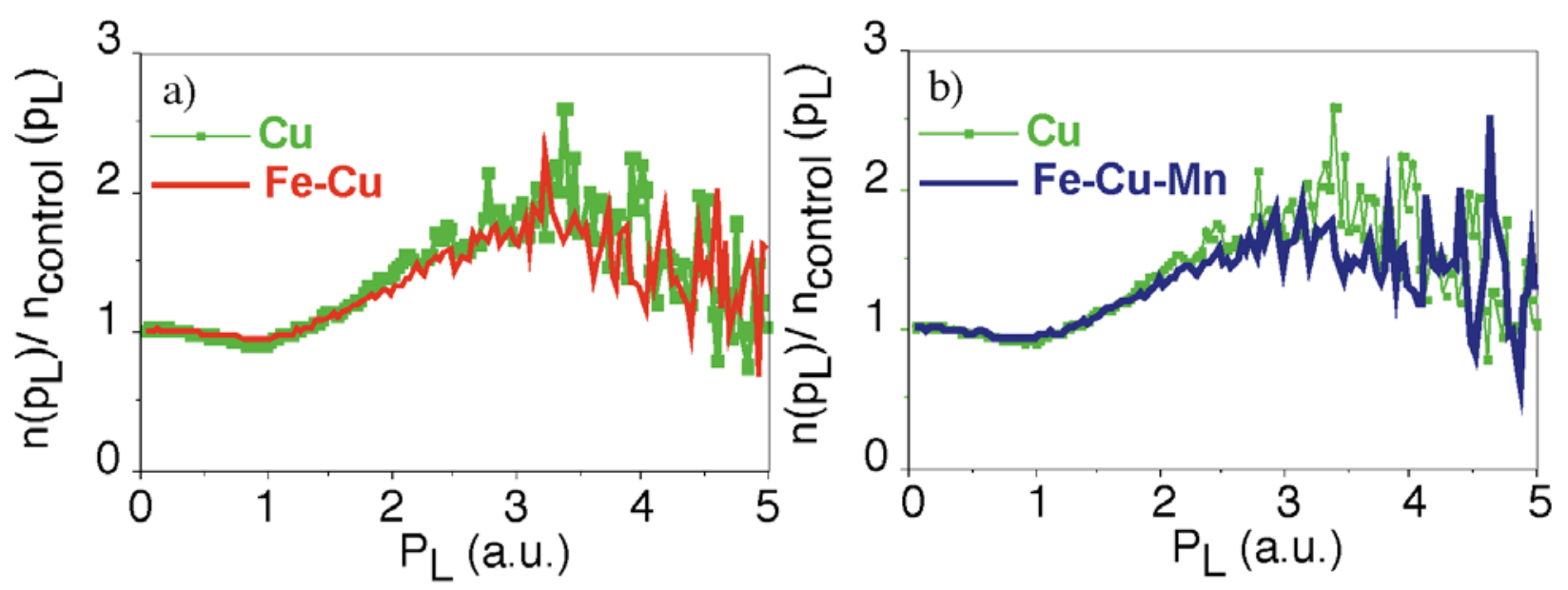

Figure 1 - Normalized Doppler-broadened spectra for $450^{\circ} \mathrm{C}, 24$ hour thermally aged for a) $\mathrm{Fe}$ $0.9 \mathrm{wt} \% \mathrm{Cu}$ and b) Fe-0.9 wt\% Cu-1.0 wt\% Mn alloy. Both spectra are nearly identical to elemental $\mathrm{Cu}$ (shown in green) and significantly different than $\mathrm{Fe}$, which would correspond to a uniform value of 1 .

\section{Neutron irradiated alloys}

The neutron irradiated SANS scattering cross-sections of both the $\mathrm{Fe}-\mathrm{Cu}$ and $\mathrm{Fe}-\mathrm{Cu}-\mathrm{Mn}$ alloys are inconsistent with the presence of only one scattering feature to a high level of statistical confidence. However, two-feature (labeled 1 and 2), log-normal size distributions provide excellent fits to the data in both cases. For the $\mathrm{Fe}-\mathrm{Cu}$ alloy, the two-feature fit results in mean radii of 3.4 and $0.9 \mathrm{~nm}$, number densities of $4.6 \times 10^{22} / \mathrm{m}^{3}$ and $1.2 \times 10^{23} / \mathrm{m}^{3}$, volume fractions of 0.75 and $0.04 \%$ and $\mathrm{M} / \mathrm{N}$ ratios of 6.7 and 1.5 for feature 1 and 2 , respectively. The $\mathrm{M} / \mathrm{N}$ for feature 1 is consistent with nearly pure $\mathrm{Cu}$ precipitates with less than $3 \%$ vacancies and that for feature 2 is consistent with a small VSC containing about $60 \%$ copper and $40 \%$ vacancies. For the $\mathrm{Fe}-\mathrm{Cu}-\mathrm{Mn}$ alloy, the two-feature fit results in estimates of mean radii of 2.0 and $1.0 \mathrm{~nm}$, number densities of $2.3 \times 10^{23} / \mathrm{m}^{3}$ and $3.0 \times 10^{23} / \mathrm{m}^{3}$, volume fractions of 0.78 and $0.11 \%$ and $\mathrm{M} / \mathrm{N}$ ratios of 4.6 and 2.0 for feature 1 and 2 , respectively. In this case, feature 1 is consistent with CRPs that contain about $6 \% \mathrm{Mn}$ and $94 \% \mathrm{Cu}$, while feature 2 is consistent with a population of VSCs including $\mathrm{Mn}$, with about $70 \% \mathrm{Cu}$. Both the VSC and CRP number densities are higher in the $\mathrm{Fe}-\mathrm{Cu}-\mathrm{Mn}$ alloy. The CRPs are smaller in this case while the VSCs are similar in size to those found in the $\mathrm{Fe}-\mathrm{Cu}$ alloy. It is important to note that the precise numerical parameters derived from the two-feature fits are not unique and are somewhat to strongly covariant particularly when the sizes of the two features are more similar. However, the exact 
number densities and volume fractions aside, the interpretation that there are multiple features with different $\mathrm{M} / \mathrm{N}$ ratios is very robust and provides important insight on the nanofeatures that form under irradiation.

The positron lifetime analysis revealed a significant increase in the mean lifetime from 109 to 233 ps for the Fe-Cu alloy, while the Fe-Cu-Mn alloy showed a much more modest increase from 110 to $122 \mathrm{ps}$. The positron lifetime fitting procedure yielded three distinct lifetime components for the $\mathrm{Fe}-\mathrm{Cu}$ alloy. The two longer lifetime components, with lifetimes and intensities of $227.8 \mathrm{ps} / 42.5 \%$ and $520 \mathrm{ps} / 19.3 \%$ are interpreted as positrons trapping in vacancytype defects. Calculations indicate that a positron lifetime of 520 ps would be consistent with a 3 -dimensional vacancy cluster containing 50 or more vacancies and a radius of $0.5 \mathrm{~nm}$ or larger. To the best of our knowledge, this represents the first measurement of such a significant population of long-lifetime component (large vacancy clusters) in Fe-based steels or alloys irradiated at $288^{\circ} \mathrm{C}$.

Figure $2 \mathrm{a}$ and $2 \mathrm{~b}$ show the normalized Doppler broadened spectra for the $\mathrm{Fe}-\mathrm{Cu}$ and $\mathrm{Fe}-$ $\mathrm{Cu}-\mathrm{Mn}$ alloy, respectively, along with the reference spectrum for elemental $\mathrm{Cu}$. In contrast to the thermally aged case, the Doppler broadened spectrum in the irradiated $\mathrm{Fe}-\mathrm{Cu}$ alloy is not identical to elemental $\mathrm{Cu}$, but actually has a peak at low momentum [ $\mathrm{p}_{\mathrm{L}}<1$ atomic unit (a.u.)] values and shows a slight peak, indicative of $\mathrm{Cu}$ at higher $\left(\mathrm{p}_{\mathrm{L}}>\sim 2.5\right.$ a.u.) values. Consistent with the positron lifetime measurements, these coupled observations suggest significant positron trapping at vacancy-Cu cluster complexes. The Doppler broadened spectrum of the irradiated Fe$\mathrm{Cu}-\mathrm{Mn}$ alloy is again nearly identical to that of pure $\mathrm{Cu}$, although the intensity is slightly lower than the thermally aged specimen. This small difference might suggest the presence of some Mn or Fe in the CRPs. Note higher Mn enrichment is consistent with both the thermodynamic effect of the lower irradiation temperature compared to the thermally aged samples and the SANS magnetic to nuclear scattering ratio results. Overall, however, the momentum spectrum in the Fe$\mathrm{Cu}-\mathrm{Mn}$ alloy indicates that the CRPs are highly enriched in $\mathrm{Cu}$. The differences between the Fe$\mathrm{Cu}$ and $\mathrm{Fe}-\mathrm{Cu}-\mathrm{Mn}$ alloys might be attributed to the effect of sink competition between VSCs and CRPs. In the case of the $\mathrm{Fe}-\mathrm{Cu}$ alloys the lower number density of CRPs allows positrons to find the higher concentration of VSC traps. However, in the Fe-Cu-Mn alloy, the CRP and VSC densities are comparable and annihilation takes place primarily in the CRPs.
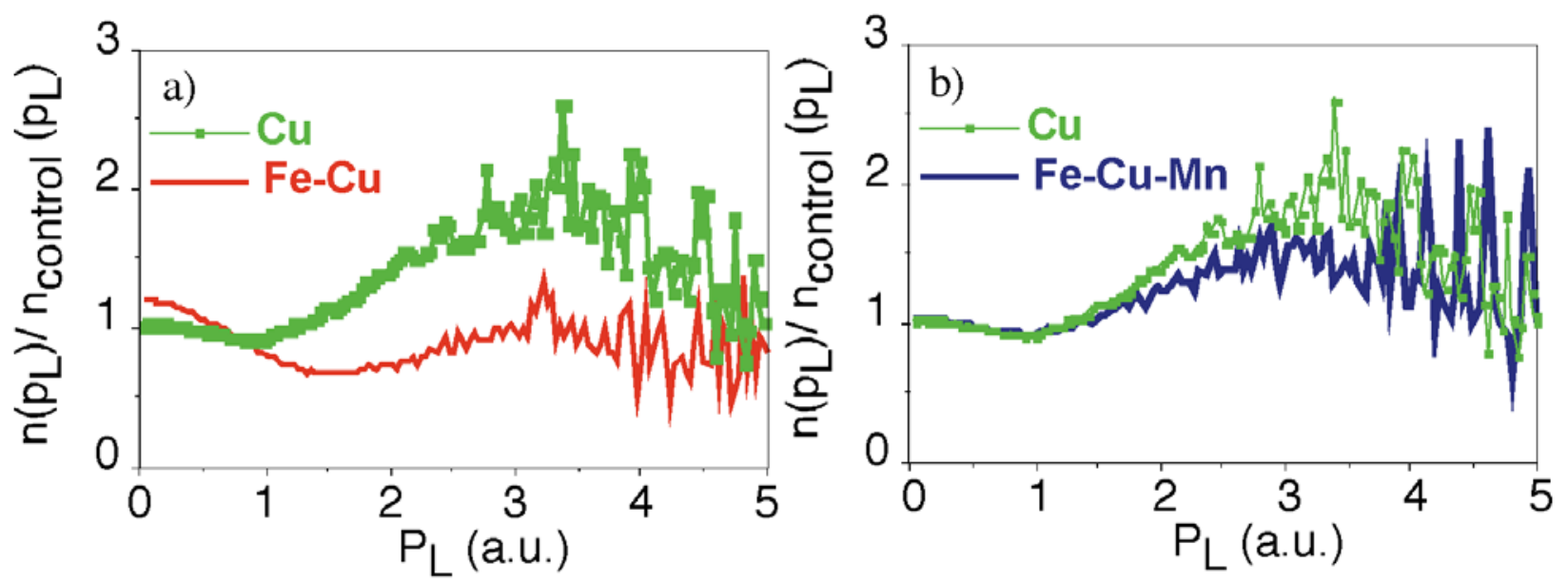

Figure 2 - Normalized Doppler-broadened spectra for $288^{\circ} \mathrm{C}$ neutron irradiated a) $\mathrm{Fe}-0.9 \mathrm{wt} \%$ $\mathrm{Cu}$ and b) Fe-0.9 wt\% Cu-1.0 wt\% Mn alloy. 


\section{CONCLUSIONS}

A complementary PAS and SANS characterization of thermally aged and neutron irradiated Fe$\mathrm{Cu}$ and $\mathrm{Fe}-\mathrm{Cu}-\mathrm{Mn}$ alloys is reported. For thermally aged alloys, both the SANS and PAS indicate the presence of a high number density of nearly pure, defect free $\mathrm{Cu}$ precipitates. The SANS and PAS results of the $288^{\circ} \mathrm{C}$ neutron irradiated $\mathrm{Fe}-\mathrm{Cu}$ alloy reveal a smaller number density of large $(\mathrm{r} \sim 3.4 \mathrm{~nm}) \mathrm{CRPs}$ and the presence of smaller vacancy-Cu cluster complexes (VSCs), which are the dominant positron trap. Notably, this is the first positron lifetime identification of large vacancy clusters in Fe-based alloys neutron irradiated at near $288^{\circ} \mathrm{C}$. Similar measurements on the neutron irradiated $\mathrm{Fe}-\mathrm{Cu}-\mathrm{Mn}$ alloy revealed the presence of CRPs with a nearly identical Doppler broadened spectrum to that of both the thermally aged alloy and elemental $\mathrm{Cu}$. This suggests that the precipitates do not contain a significant amount of Fe. Further, trapping at large vacancy complexes is not observed in the irradiated $\mathrm{Fe}-\mathrm{Cu}-\mathrm{Mn}$ alloy. This may be due to either a dominance of precipitate trapping relative to any vacancy-solute $(\mathrm{Cu}-\mathrm{Mn})$ complexes present in this case, or to the suppression of the formation of larger vacancy clusters by the Mn. Of course both effects may occur in combination. Future work will focus on further clarifying these issues.

The authors acknowledge the contributions of Doug Klingensmith (UCSB) to the SANS measurements. This work is performed under the auspices of the U.S. Department of Energy by the University of California Lawrence Livermore National Laboratory under Contract No. W7405-Eng-48 and the U.S. Nuclear Regulatory Commission under Contract No. NRC-04-94-049.

\section{REFERENCES}

1. G. R. Odette, Scripta Met. 11, (1983) 1183.

2. $\quad$ G. R. Odette, MRS Soc. Symp. Proc. 373 (1995) 137.

3. $\quad$ P. Pareige and M. K. Miller, App. Surf. Sci. 94/95 (1996) 370.

4. M. K. Miller, P. Pareige and M. G. Burke, Materials Characterization, 44 (2000) 235.

5. P. Pareige, PhD Dissertation, Rouen University (1994).

6. P. A. Beaven, F. Frisius, R. Kampmann, R. Wagner, and J. R. Hawthorne, ASTMSTP1011, American Society for Testing and Materials, Philadelphia, PA (1989) 243.

7. $\quad$ G. R. Odette and G. E. Lucas, Radiation Effects \& Defects in Solids 144 (1998) 189.

8. E. V. Mader, Ph.D. Dissertation, University of California Santa Barbara (1995).

9. B. D. Wirth, Ph.D. Dissertation, University of California, Santa Barbara (1998).

10. E. D. Eason, J. E. Wright, and G. R. Odette, Improved Embrittlement Correlations for Reactor Pressure Vessel Steels, NUREG/CR-6551, (1998).

11. G. R. Odette and B. D. Wirth, J. Nucl. Mater. 251 (1997) 157.

12. G. R. Odette, C. L. Liu and B. D. Wirth, MRS Symp. Proc. 439 (1997) 457.

13. M.J. Puska, P. Lanki and R. M. Niemen, J. Phys. Condens. Matter 1 (1989) 6081.

14. C. J. Glinka, J. M. Rowe and J. G. laRock, J. of Applied Crystallography 19 (1986) 427.

15. R.H. Howell, P.A. Sterne, J. Hartley, T.E. Cowan, Appl. Surf. Sci. 149 (1999) 103.

16. P. Asoka-Kumar, M. Alatalo, V. J. Ghosh, A. C. Kruseman, B. Nielsen and K. G. Lynn, Phys. Rev. Letters 77 (1996) 2097.

17. Y. Nagai, M Hasegawa, Z. Tang, A. Hempel, K. Yubata, T. Shimamura, Y. Kawazoe, A. Kawai and F. Kano, Phys. Rev. B 61 (2000) 6574. 